\title{
The two hit hypothesis: An improved method for siRNA-mediated gene silencing in stimulated primary human T cells ${ }^{\text {is }}$
}

\author{
Michael Freeley*, Aideen Long
}

Department of Clinical Medicine, Institute of Molecular Medicine, Trinity College Dublin, Dublin 2, Ireland

\begin{abstract}
Small interfering RNAs (siRNAs) have revolutionised cellular and molecular biology by uncovering new roles for genes in various biological processes and by providing new opportunities to silence gene expression for therapeutic purposes. A limiting factor of siRNA-mediated gene silencing, however, is the ability to efficiently deliver these molecules into hard-to-transfect cell types such as primary T cells. Nucleofection ${ }^{\circledR}$ technology, marketed by Lonza (Amaxa $($ ), is an electroporation-based method that is commonly used for the delivery of siRNAs and plasmids into primary T cells. In this study we found that the recommended programs for nucleofection of stimulated primary human T cells with siRNAs inhibited cellular proliferation and were associated with a significant loss of cell viability. Furthermore, viable cells that survived the nucleofection procedure were perturbed in their ability to polarise in response to chemokine stimulation in comparison to mock nucleofections. We therefore evaluated other nucleofection programs and highlight one that resulted in significant silencing at the protein level following nucleofection with siRNAs, while maintaining cell viability and responsiveness to chemokine stimulation. Further optimisation of this method revealed that a second nucleofection with siRNAs after $72 \mathrm{~h}$ significantly increased silencing compared to a single nucleofection. This new and improved two-hit nucleofection method for siRNA-mediated gene silencing in stimulated primary human T cells will therefore permit the investigation of genes and signalling pathways in the $\mathrm{T}$ cell immune response.
\end{abstract}

Keywords: T cell; Nucleofection; siRNA; Gene silencing; Transfection

\section{Introduction}

$\mathrm{T}$ cells are essential mediators of the adaptive immune response but many of the proteins and signalling cascades that regulate the function of these cells have yet to be fully defined (Bradley, 2003; Song et al., 2008). Characterisation of such proteins in the context of $\mathrm{T}$ cell function offers the potential to target these proteins therapeutically in order to modulate $\mathrm{T}$ cell-mediated inflammatory/autoimmune

\footnotetext{
मे This work was supported by the Higher Education Authority Programme for Research in Third-Level Institutions (HEA PRTLI).

* Corresponding author. Tel.: +3531 8963266; fax: +35318962043. E-mail address: freeleym@tcd.ie (M. Freeley).
}

diseases, immunosuppression and cancer (June et al., 2009; Steward-Tharp et al., 2010; Restifo et al., 2012). The proteins and signalling pathways that regulate the $\mathrm{T}$ cell immune response have primarily been elucidated with pharmacological inhibitors (Ghoreschi et al., 2009), over-expression of dominant-negative mutants (Perlmutter and Alberola-Ila, 1996) and gene-deficient knockout mice (Saveliev and Tybulewicz, 2009). However, such strategies can have several disadvantages. For example, it is well known that many pharmacological inhibitors exhibit lack of specificity (Ghoreschi et al., 2009; Cohen, 2010), while generation of knockout mice is costly, time consuming and may result in embryonic lethality (Saveliev and Tybulewicz, 2009). Although small interfering RNA (siRNA)-mediated silencing/ knockdown of target gene expression represents a new, highlyspecific and relatively inexpensive approach for dissecting gene function (Aagaard and Rossi, 2007; Singh et al., 2011), 
A

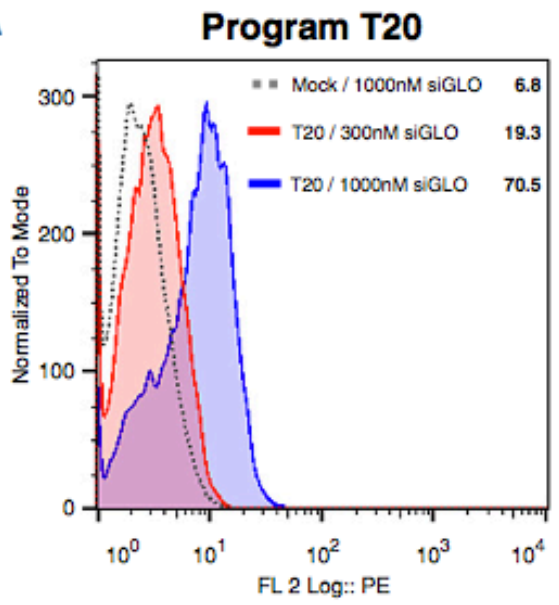

Program T23

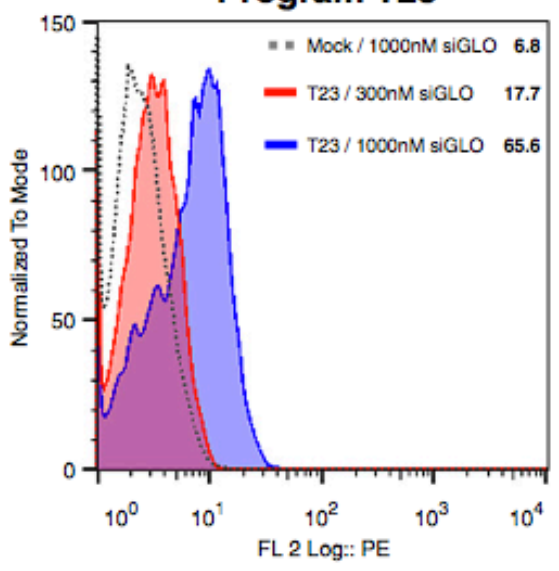

B

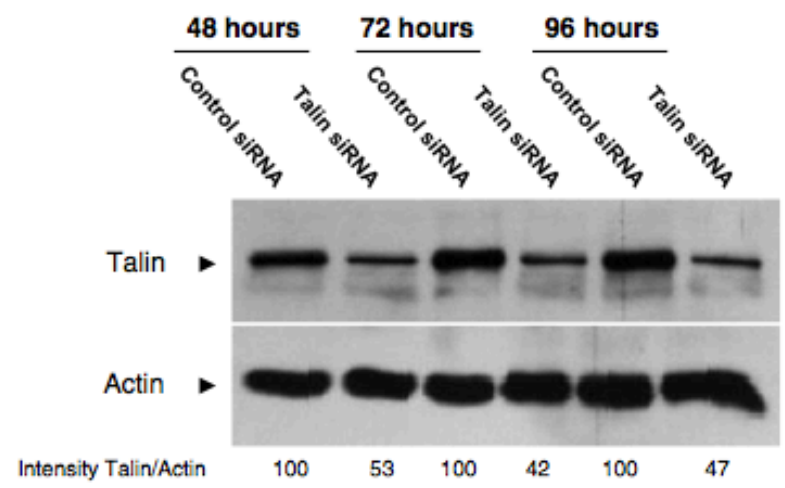

Fig. 1. Delivery of siRNAs and gene silencing in stimulated $T$ cells using the recommended nucleofection programs. (A) PHA/lL-2-stimulated T cells were nucleofected with the indicated concentrations of siGLO siRNAs using programs T20 or T23. The cells were analysed by flow cytometry after 4 h. The numbers highlighted in bold in the flow cytometry histogram plots indicate the $\%$ transfected cells (B) $\mathrm{T}$ cells were nucleofected with $1000 \mathrm{nM}$ non-targeting control siRNAs or siRNAs targeting Talin using program T20. Portions of the cells were harvested at 48,72 and $96 \mathrm{~h}$ and cell lysates were probed by Western blotting with antibodies to Talin or Actin as a loading control. Densitometry was used to estimate the intensity of the bands and is expressed as Intensity Talin/Actin. T cells from an individual donor are presented in panels $\mathrm{A}$ and $\mathrm{B}$ and are representative of three similar experiments.

the use of such technology in T cells has been limited due to inefficient siRNA delivery methods, particularly in primary $T$ cells isolated from blood donors. Primary $\mathrm{T}$ cells are generally refractory to lipid-based transfection methods and thus require viral vector delivery systems or electroporation (Hurez et al., 2002; June et al., 2009). Viral vectors are highly efficient means of delivering genetic material into cells but are labour intensive, costly and require specialist bio-safety equipment, while loss of cell viability is a common issue with electroporation as a result of the high voltages that transiently permeabilise the cell membrane (Hurez et al., 2002; Gehl, 2003; June et al., 2009).

Nucleofection@ is an electroporation-based procedure that was developed by Lonza (formerly known as Amaxa®), consisting of a proprietary device, cell type-specific solutions and optimised programs for the delivery of siRNAs and plasmids into cells, including hard-to-transfect cell types (Gresch et al., 2004). Nucleofection is now one of the most commonly used methods for the delivery of siRNAs and plasmids into primary $\mathrm{T}$ cells. In our work on investigating the role of candidate proteins in T cell activation and migration using siRNA-mediated gene silencing approaches, we found that the recommended programs for nucleofection of
siRNAs into PHA/IL-2 or anti-CD3/CD28-stimulated primary human $\mathrm{T}$ cells were associated with a significant loss of cell proliferation and cell viability. Furthermore, viable cells that survived the nucleofection procedure were perturbed in their responsiveness to chemokine stimulation. We therefore evaluated a number of other nucleofection programs and demonstrate effective gene silencing using an optimised two-hit nucleofection protocol for stimulated primary human $\mathrm{T}$ cells that preserves cell viability and results in improved responsiveness to chemokine stimulation.

\section{Materials and methods}

\subsection{Reagents}

The T cell Nucleofector $®$ kit (T cell nucleofector $\circledast$ solution, cuvettes and pmaxGFP@ plasmid) were obtained from Lonza (formerly known as Amaxa $\otimes^{-}$Cologne, Germany). Ingenio electroporation solution and cuvettes were obtained from Mirus Bio (Madison, WI). SMARTpool On-Target Plus siRNAs to human L-plastin, Talin, protein kinase C (PKC) $\beta$, fluorescentlylabelled siRNA ( were obtained from Thermo Scientific Dharmacon (Lafayette, 
CO). The fluorescently-labelled siRNA to human GAPDH (IBONI@) was from Riboxx Life Sciences (Radebeul, Germany). Lymphoprep solution was obtained from Axis Shield (Dundee, UK). Interleukin-2 (IL-2) and SDF-1 $\alpha$ (CXCL12) were obtained from PeproTech (London, UK). Anti-CD28 was obtained from Ancell Corporation (Bayport, MN). RPMI-1640, foetal calf serum and penicillin/streptomycin solution were obtained from Gibco BRL (Life Technologies, Paisley, UK). Anti-L-plastin antibody (clone 4A.1) was obtained from Thermo Fisher Scientific (Fremont, California). Anti-Talin antibody, anti-actin antibody, phytohaemagglutinin (PHA), goat anti-mouse IgG, paraformaldehyde, bovine serum albumin (BSA), Triton X100, phalloidin-TRITC and trypan blue were obtained from SigmaAldrich (St. Louis, MO). CellTiter-Blue@ cell viability solution was obtained from Promega (Madison, WI). Anti-CD3 and anti-PKC $\beta$ antibodies were obtained from BD Biosciences (Oxford, UK). The $\mathrm{CD} 4^{+}$human $\mathrm{T}$ cell enrichment kit was obtained from STEMCELL Technologies (Grenoble, France). Horseradish-peroxidise (HRP)-conjugated goat anti-mouse IgG was obtained from Cell Signaling Technology (Beverly, MA). Hoechst 33258 was obtained from Molecular ProbesInvitrogen (Paisley, UK).

\subsection{Cell culture}

Peripheral human T cell blasts were expanded from buffy coat blood packs obtained from the Irish Blood Transfusion Service in St. James's Hospital Dublin using PHA and IL-2, as described (Lefort and Kim, 2010). In brief, buffy coat blood packs $(\sim 50 \mathrm{ml})$ were diluted with an equal volume of sterile PBS and mixed well. The blood was carefully overlaid on an equal volume of Lymphoprep solution and centrifuged at $1200 \mathrm{~g}$ for $\mathbf{2 0} \mathrm{min}$ without any brake. Peripheral blood mononuclear cells were then removed from the liquid/Lymphoprep interface and washed three times in RPMI-1640 containing $10 \%$ foetal calf serum and penicillin/streptomycin (complete medium). The peripheral blood mononuclear cells were re-suspended in complete medium and depleted of monocytes by incubating in $\mathrm{T}-175 \mathrm{~cm}^{2}$ flasks for $2 \mathrm{~h}$ at $37^{\circ} \mathrm{C}$. Non-adherent cells were recovered and incubated in T-175 $\mathrm{cm}^{2}$ flasks for a second round of monocyte depletion for $2 \mathrm{~h}$ at $37^{\circ} \mathrm{C}$. Non-adherent cells were recovered, re-suspended at $2 \times 10^{6} \mathrm{cells} / \mathrm{ml}$ in complete medium and stimulated with $2 \mu \mathrm{g} / \mathrm{ml}$ PHA for $72 \mathrm{~h}$ at $37^{\circ} \mathrm{C}$ in complete RPMI-1640. The cells were recovered, washed three times with complete medium and re-suspended at $2 \times 10^{6} \mathrm{cells} / \mathrm{ml}$ in complete medium. Recombinant IL-2 was added to a final concentration of $20 \mathrm{ng} / \mathrm{ml}$ and the cells were incubated for 5 days at $37{ }^{\circ} \mathrm{C}$. Fresh IL-2 and complete medium were added after 2-3 days to maintain the cell number between 2 and $4 \times 10^{6}$ cells/ml. This expansion protocol results in $>98 \% \mathrm{CD}^{+} \mathrm{T}$ cells, with the proportion of $\mathrm{T}$ cell subsets reported as $83 \% \mathrm{CD}^{+}, 15 \% \mathrm{CD}^{+}$and $<1 \%$ $\mathrm{CD}^{+} / \mathrm{CD}^{+}$(Lefort and Kim, 2010). Human $\mathrm{CD}^{+} \mathrm{T}$ cells were isolated from monocyte-depleted peripheral blood mononuclear cells using the $\mathrm{CD} 4^{+}$human T cell enrichment kit according to the manufacturers' instruction. The cells were subsequently incubated in plates containing immobilised anti-CD3/CD28 antibodies for 3 days at $37{ }^{\circ} \mathrm{C}(10 \mu \mathrm{g} / \mathrm{ml}$ goat anti-mouse IgG in PBS coated overnight at $4{ }^{\circ} \mathrm{C}$, followed by incubation with $5 \mu \mathrm{g} / \mathrm{ml}$ anti-CD3 and $1 \mu \mathrm{g} / \mathrm{ml}$ anti-CD28 antibodies for $2 \mathrm{~h}$ at $37^{\circ} \mathrm{C}$ ). The cells were recovered and cultured in complete medium containing $20 \mathrm{ng} / \mathrm{ml} \mathrm{IL-2}$ for another 5 days. Fresh IL-2 and complete medium were added after 2-3 days to maintain the cell number between 2 and $4 \times 10^{6}$ cells $/ \mathrm{ml}$.

\subsection{Nucleofection of $T$ cells}

T cells were nucleofected with siRNAs and plasmids according to the protocols supplied by Lonza. In brief, PHA/ IL-2-stimulated T cells or anti-CD3/CD28-stimulated CD4 ${ }^{+} \mathrm{T}$ cells were harvested on day 5 after culturing in IL-2 and viable cells were isolated using Lymphoprep density gradient centrifugation before nucleofection. $5 \times 10^{6} \mathrm{~T}$ cells per nucleofection were pelleted, washed once in sterile PBS and resuspended in $100 \mu \mathrm{l}$ of $\mathrm{T}$ cell Nucleofector® solution (Lonza). The indicated concentration of siRNAs were added to the cell suspensions, mixed gently and immediately transferred to the relevant cuvettes. The cuvettes were placed in the Lonza nucleofection device and pulsed using the appropriate program. The cells were removed from the cuvette and incubated in RPMI-1640 containing $10 \%$ foetal calf serum without antibiotics. IL-2 $(20 \mathrm{ng} / \mathrm{ml})$ was added to the cultures after $4 \mathrm{~h}$. Control nucleofections were performed in parallel whereby $5 \times 10^{6} \mathrm{~T}$ cells were incubated in $100 \mu \mathrm{T}$ cell nucleofection solution (Mock) or $100 \mu \mathrm{l}$ PBS in the presence of siRNAs but these cells were not subjected to nucleofection. Where indicated, $\mathrm{T}$ cells were nucleofected again with a second round of siRNAs after $72 \mathrm{~h}$ and incubated for a further $48 \mathrm{~h}$ in RPMI-1640 containing $10 \%$ foetal calf serum and IL-2 before harvesting. For this second round of nucleofection, individual cuvettes were re-used by washing in $\mathrm{dH}_{2} \mathrm{O}$ before leaving them to dry overnight at room temperature. The cuvettes were sterilised by placing them inside the cell culture hood under UV

\footnotetext{
Fig. 2. Nucleofection® of stimulated primary human T cells with programs T20 or T23 result in a loss of cell viability. (A) PHA/IL-2-stimulated T cells were nucleofected with the indicated concentrations of siGLO siRNAs. Cell viability was measured after $72 \mathrm{~h}$ by trypan blue staining. T cells subjected to mock nucleofection with $1000 \mathrm{nM}$ siGLO served as a nucleofection control. (B). T cells were nucleofected with non-targeting control siRNAs or siRNAs targeting Talin using program T20. Control nucleofections consisted of mock nucleofections or T cells incubated in PBS in the presence of non-targeting control siRNAs. Cell viability was measured after $72 \mathrm{~h}$. (C) CD4 ${ }^{+} \mathrm{T}$ cells stimulated with anti-CD3/CD28 and IL-2 were nucleofected with $1000 \mathrm{nM}$ siGLO using program T20. Mock nucleofections with $1000 \mathrm{nM}$ siGLO served as a control. The cells were analysed by flow cytometry after $4 \mathrm{~h}$. The numbers highlighted in bold in the flow cytometry histogram plot indicate the $\%$ transfected cells. (D) Cell viability of stimulated $\mathrm{CD} 4^{+} \mathrm{T}$ cells after $72 \mathrm{~h}$ following nucleofection with program T20. (E, F) PHA/IL-2-stimulated or stimulated CD4 ${ }^{+} \mathrm{T}$ cells were nucleofected with program T20 with $1000 \mathrm{nM}$ siGLO. After $72 \mathrm{~h}$, equal numbers of viable cells from incubated with CellTiter-Blue and the levels of fluorescence were measured after $4 \mathrm{~h}$. The mean and standard deviations are indicated on the graphs. NS indicates no significance. (G) Control siRNAs were nucleofected into T cells using programs T20 or T23. Mock nucleofections were prepared in parallel. After 72 h, equal numbers of viable cells were stimulated with SDF- $1 \alpha$ for 10 min. The cells were fixed and stained with Hoechst 33258 and phalloidin-TRITC. High Content Analysis was used to determine the total number of cells that re-distributed their F-actin to one side of the cell using the Cell Intensity CV parameter. Representative images of cells with different Cell Intensity CV values are depicted. The data in this figure is representative of three similar experiments.
} 
A

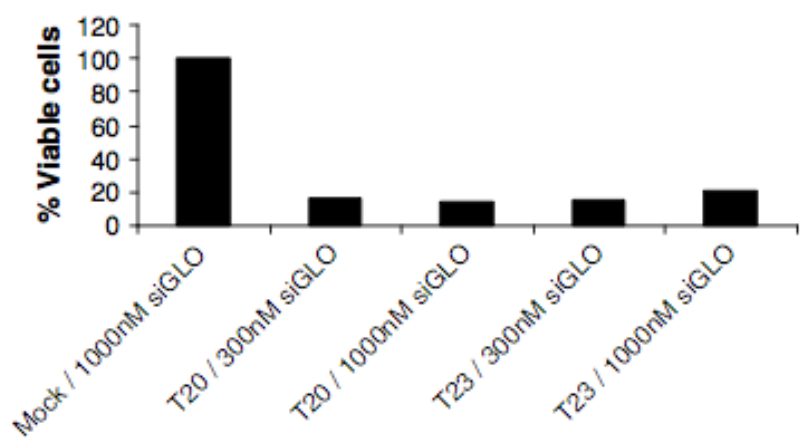

C

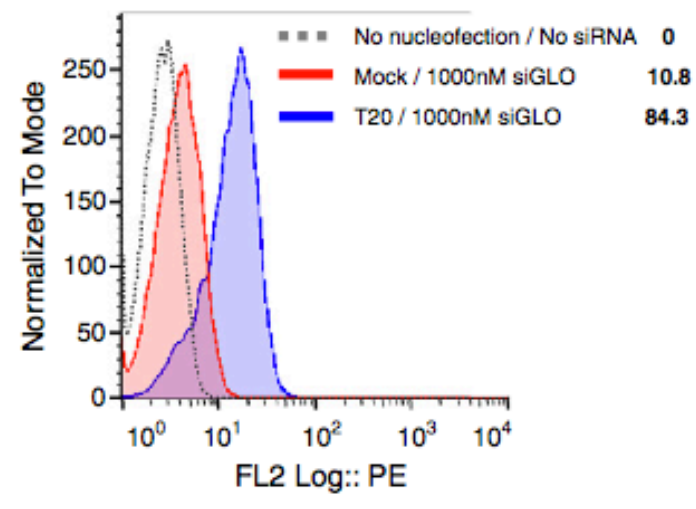

E

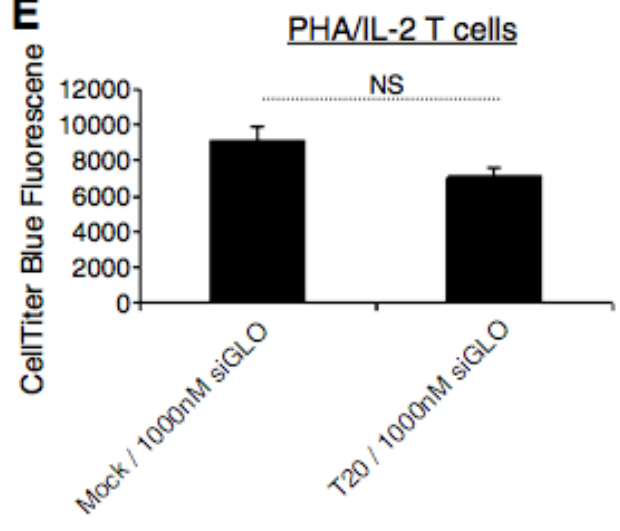

G

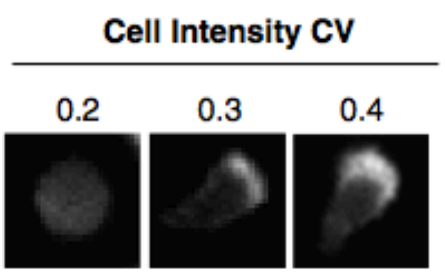

B

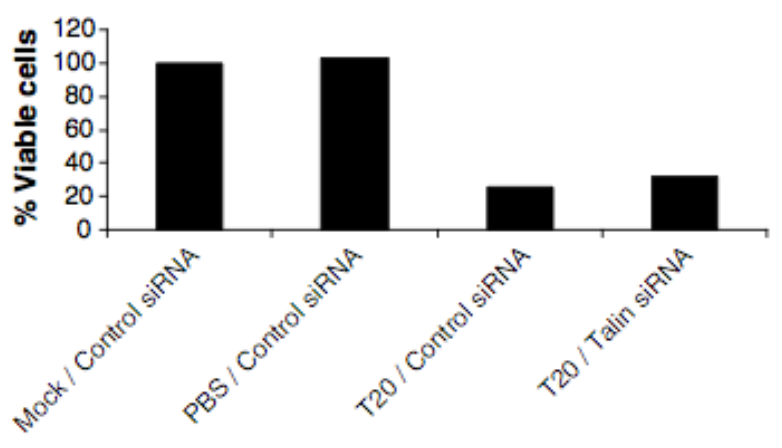

D

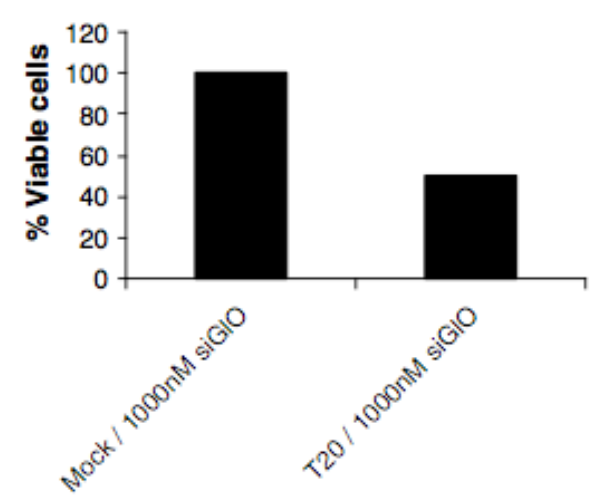

F
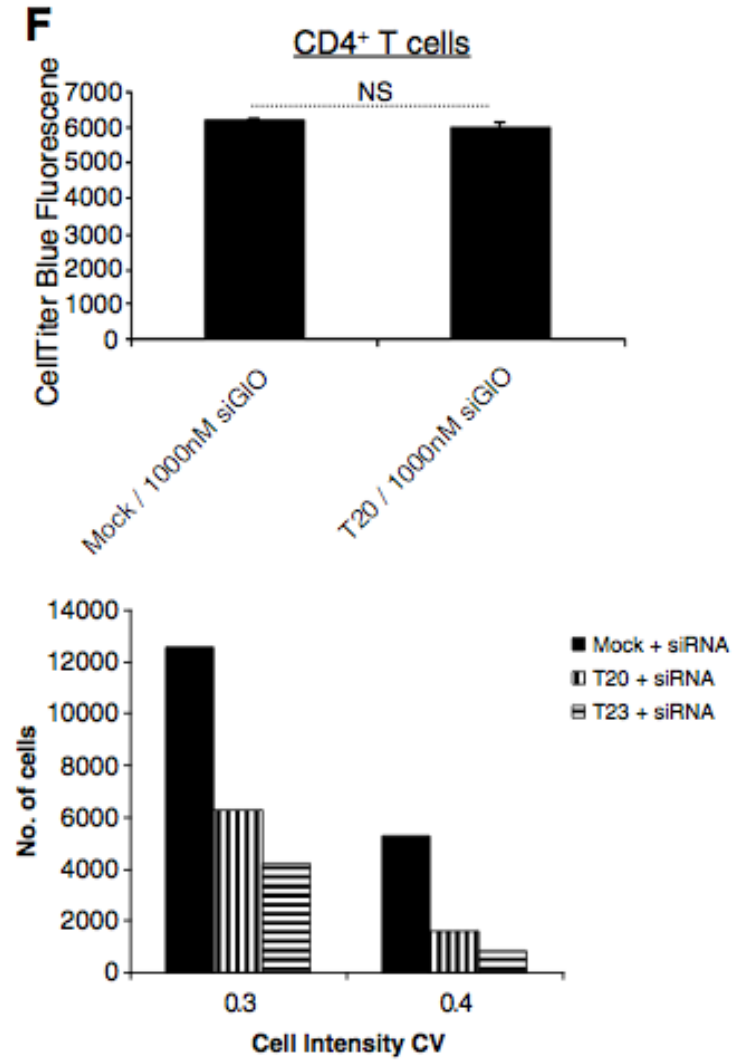
light for $15 \mathrm{~min}$ before use. Where indicated, Ingenio electroporation solution (Mirus Bio) was used for nucleofection of $\mathrm{T}$ cells instead of the T cell Nucleofector solution (Lonza) and the nucleofection procedure was carried out as already described.

\subsection{Cell viability and CellTiter-Blue® assays}

Cell viability was determined by mixing cell suspensions with trypan blue and counting viable cells with a haemocytometer. Healthy cells exclude trypan blue whereas nonviable cells take up the stain. Because trypan blue does not distinguish between healthy cells and cells that are alive but have lost cellular function, we determined whether trypan-negative nucleofected cells were functional or not. For this assay, we used the CellTiter-Blue $®$ assay which measures the ability of living cells to convert resazurin to the fluorescent resorufin. The assay was carried out according to the manufacturers' instructions. In brief, mock nucleofections and cells subjected to nucleofection were harvested after $72 \mathrm{~h}$ and cell viability was determined by trypan blue staining. The cell concentration was adjusted to $1 \times 10^{6}$ viable cells/ml and $100 \mu \mathrm{l}$ of cell suspensions (in triplicate) were incubated with $20 \mu \mathrm{l}$ of CellTiter-Blue in 96-well plates and incubated for $4 \mathrm{~h}$ at $37^{\circ} \mathrm{C}$. The levels of fluorescence were quantified with a fluorometer (Wallac VICTOR, PerkinElmer). These assays were optimised in preliminary assays using a range of $\mathrm{T}$ cell concentrations and it was found that a cell concentration of $1 \times 10^{6} \mathrm{cells} / \mathrm{ml}$ ensured that the fluorescence values were in the linear range after $4 \mathrm{~h}$. Background fluorescence values were determined by incubating complete cell culture medium with CellTiter-Blue $\otimes$ and subtracting these values from all other readings.

\subsection{Flow cytometry}

The delivery of siRNAs into stimulated human T cells was determined using fluorescently-labelled siRNAs and quantified by flow cytometry. Cells were harvested at the indicated time-points and washed twice by centrifuging the cells and re-suspending them in PBS. Live cells were then analysed on a CyAn flow cytometer (Beckman Coulter Ltd, London). Non-viable cells were clearly distinguishable on flow cytometry plots as a loss in forward scatter and side scatter and were excluded from the analysis. Flow cytometry data was analysed with FlowJo vX0.6 software (Tree Star, Ashland, OR). The delivery of plasmids encoding GFP into stimulated $\mathrm{T}$ cells was visualised with an inverted fluorescent microscope (Nikon Eclipse TE300) and quantified by flow cytometry as above.

\subsection{SDS-PAGE and Western blotting}

$\mathrm{T}$ cells were harvested at the indicted times following nucleofection, enumerated and lysed in ice-cold cell lysis buffer (1\% NP40, $20 \mathrm{mM}$ Tris- $\mathrm{HCl}$ ( $\mathrm{pH} \mathrm{7.4),} 150 \mathrm{mM} \mathrm{NaCl}$, $5 \mathrm{mM}$ EDTA, $5 \mathrm{mM}$ EGTA, $5 \mathrm{mM}$ sodium fluoride, $5 \mathrm{mM}$ sodium pyrophosphate, $1 \mathrm{mM}$ sodium orthovanadate, $1 \mathrm{mM}$ PMSF and $10 \mu \mathrm{g} / \mathrm{ml}$ leupeptin) for at least $30 \mathrm{~min}$ on ice with intermittent vortexing of the sample. Detergent-insoluble material and nuclei were removed by centrifugation for $5 \mathrm{~min}$ at $10000 \mathrm{rpm}$. An equal volume of $2 \times$ SDS-PAGE sample buffer was added to the lysates. The samples were then incubated for $5 \mathrm{~min}$ at $100^{\circ} \mathrm{C}$. The samples were cooled and the lysate corresponding to $2.5 \times 10^{5}$ cells was resolved on $10 \%$ SDS-PAGE gels and transferred to PVDF membrane by Western blotting. After blocking in $5 \%$ Marvel milk powder in TBS- $0.05 \%$ Tween for $1 \mathrm{~h}$ at room temperature, the membranes were washed three times in TBS-0.05\% Tween. The membranes were then incubated overnight at $4{ }^{\circ} \mathrm{C}$ with diluted primary antibodies in 5\% BSA/TBS-0.05\% Tween with gentle rocking. After three washes in TBS-0.05\% Tween, the membranes were incubated with HRP-conjugated goat antimouse IgG antibodies for $2 \mathrm{~h}$ at room temperature. After three further washes in TBS-0.05\% Tween, the membranes were incubated with HRP substrate solution (Haan and Behrmann, 2007) and exposed to light sensitive film for various times. Densitometry was used to estimate the intensity of bands on the Western blot films using Kodak 1D Image Analysis Software (New Haven, CT).

\subsection{Chemokine stimulation and high content image analysis}

T cells were enumerated after $72 \mathrm{~h}$ following nucleofection and $2 \times 10^{5}$ viable cells were centrifuged and re-suspended in $400 \mu \mathrm{l}$ of serum-free RPMI-1640 (0.5\% w/v BSA in RPMI-1640). The cells were incubated for $1 \mathrm{~h}$ at $37^{\circ} \mathrm{C}$ to starve the cells of growth factors. The cell suspensions were then divided into two tubes; one tube was stimulated with $100 \mathrm{ng} / \mathrm{ml} \mathrm{SDF}-1 \alpha$ at $37^{\circ} \mathrm{C}$ for $10 \mathrm{~min}$ while the other tube was left unstimulated for a similar period of time at $37^{\circ} \mathrm{C}$. An equal volume of $8 \%$ paraformaldehyde was then added to both tubes and incubated for $15 \mathrm{~min}$ at $37^{\circ} \mathrm{C}$ to fix the cells. The cells were centrifuged at $3000 \mathrm{rpm}$ for $3 \mathrm{~min}$ and permeabilised with $0.3 \%$ Triton $\times 100$

Fig. 3. Evaluation of other nucleofection programs for transfection of stimulated human $\mathrm{T}$ cells. (A) PHA/L-2-stimulated T cells were nucleofected with 1000 nM siGLO using the indicated programs. The cells were analysed by flow cytometry after $4 \mathrm{~h}$. Cell viability was measured after $72 \mathrm{~h}$. The mean and standard deviation (SD) transfection and cell viability values are indicated ( $\mathrm{n}=2$ donors) (B) T cells were nucleofected with $1000 \mathrm{nM}$ control siRNAs or siRNAs targeting Talin or L-plastin. Portions of the cells were harvested at 48,72 and 96 h. Lysates were probed by Western blotting with antibodies to Talin or L-plastin. The expression levels of Talin were used as a loading control for gene silencing of L-plastin, whereas L-plastin was used as a loading control for gene silencing of Talin. Densitometry was used to estimate the intensity of the bands and is expressed as Intensity L-plastin/Talin or Intensity Talin/L-plastin. (C) Control siRNAs were nucleofected into T cells using programs T20 or T7. Mock nucleofections were prepared in parallel. After 72 h, equal numbers of viable cells were stimulated with SDF- $1 \alpha$ for $10 \mathrm{~min}$. The cells were fixed and stained with Hoechst 33258 and phalloidin-TRITC. High Content Analysis was used to determine the total number of cells that re-distributed their F-actin to one side of the cell using the Cell Intensity CV parameter. Representative images of cells with different Cell Intensity CV values are depicted. (D) T cells were re-suspended with the $\mathrm{T}$ cell nucleofector solution (Lonza) or the Ingenio electroporation solution (Mirus Bio) and $1000 \mathrm{nM}$ siGLO was added. The cells were subjected to nucleofection using program T7. The cells were analysed by flow cytometry after $4 \mathrm{~h}$. (E) T cells were re-suspended with the $\mathrm{T}$ cell nucleofector solution (Lonza) or the Ingenio electroporation solution (Mirus Bio) and $1000 \mathrm{nM}$ control siRNAs or siRNAs targeting Talin were added. Program T7 was used for nucleofection. After $72 \mathrm{~h}$, the cells were harvested and lysates were probed by Western blotting with an antibody to Talin or $\mathrm{L}$-plastin (loading control). The data in this figure is representative of two similar experiments. 
A

\begin{tabular}{|c|c|c|}
\hline Program / siRNA & $\begin{array}{c}\text { \% Transfected cells (4 hours) } \\
\text { (Mean }+/ \text { - SD) }\end{array}$ & $\begin{array}{c}\text { \% Viable cells (72 hours) } \\
\text { (Mean +/- SD) }\end{array}$ \\
\hline No nucleofection/ No siRNA & $1+/-1$ & $100+/-0$ \\
\hline MOCK/ siGLO & $8+6$ & $103+/-2$ \\
\hline T20/siGLO & $77+/-16$ & $36+/-4$ \\
\hline T3/siGLO & $16+/-0$ & $103+/-3$ \\
\hline T6/siGLO & $35+/-7$ & $104+/-5$ \\
\hline T7/ siGLO & $39+/-12$ & $101+/-4$ \\
\hline T9/ siGLO & $58+/-11$ & $68+/-0$ \\
\hline P7/ siGLO & $29+/-6$ & $94+/-12$ \\
\hline
\end{tabular}

B

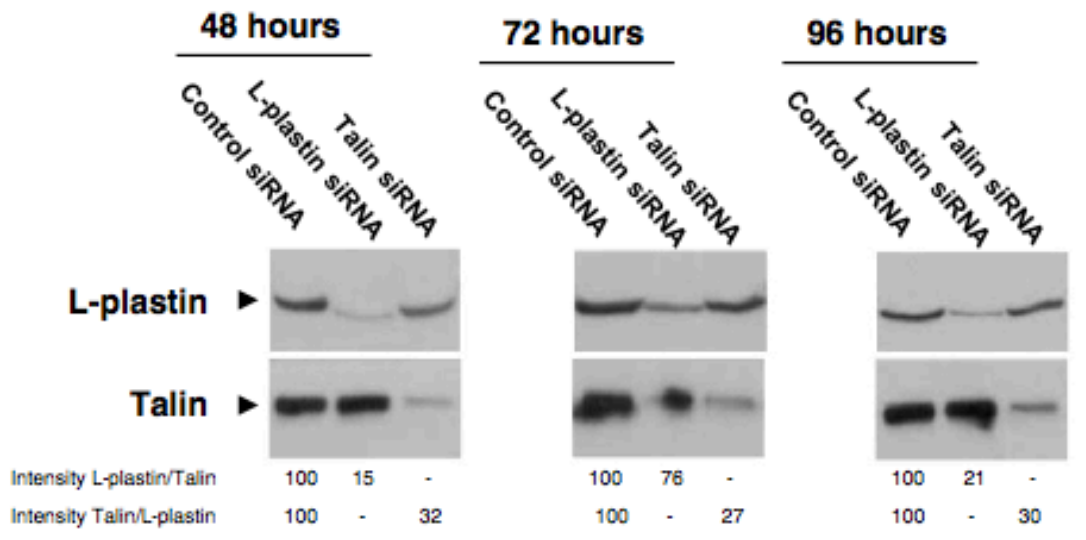

C

\begin{tabular}{c|c|c}
\multicolumn{3}{c}{ Cell Intensity CV } \\
\hline 0.15 & 0.2 & 0.25 \\
\hline & & \\
\hline
\end{tabular}

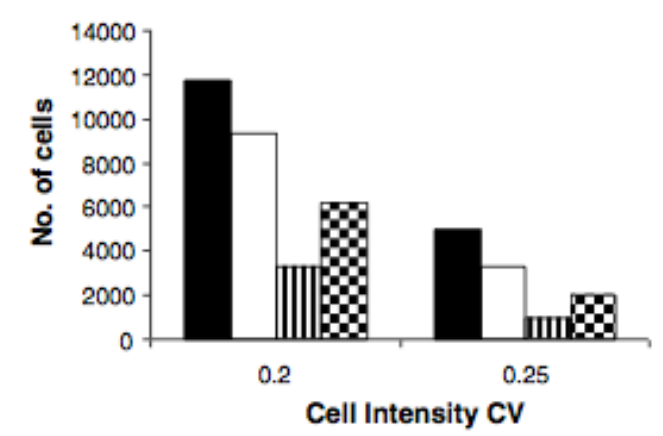

- PBS + SIRNA

口 Mock + siRNA

D T20 + SiRNA

Q T7 + siRNA

D

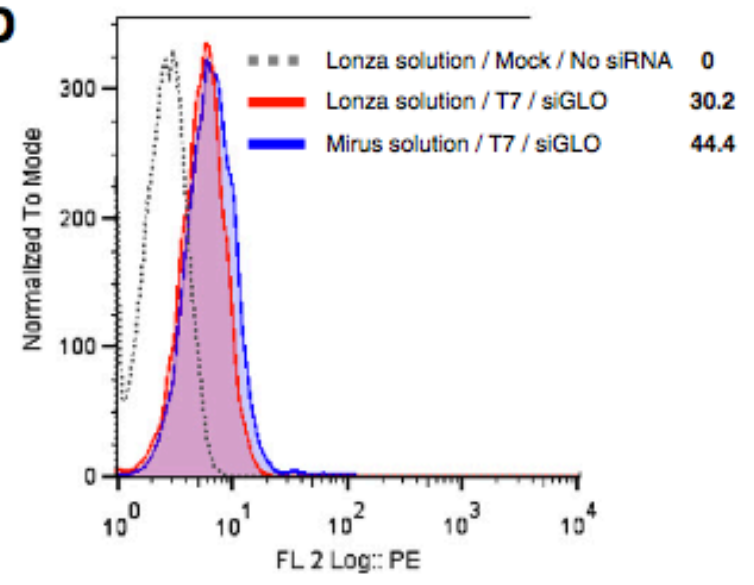

E

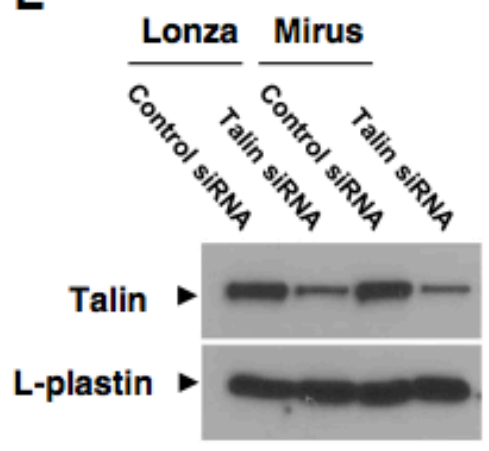

Intensity Talir/L-plastin $\quad 100 \quad 31 \quad 100 \quad 20$ 
in PBS for $5 \mathrm{~min}$ at room temperature. The cells were centrifuged again and blocked in 3\% BSA in PBS for 30 min at room temperature. The cells were subsequently incubated with $200 \mu \mathrm{g} / \mathrm{ml}$ phalloidin-TRITC and $1 \mu \mathrm{g} / \mathrm{ml}$ Hoechst 33258 in $3 \% \mathrm{BSA} / \mathrm{PBS}$ for $1 \mathrm{~h}$ at room temperature to label filamentous actin (F-actin) and the nucleus, respectively. After 3 washes in PBS, the cells were added into Nunc 96-well plates, allowed to settle and imaged under $10 \times$ magnification using the IN Cell Analyser High Content Analysis (HCA) Imaging System (GE Healthcare, UK). A total of 42 fields were acquired for each sample, resulting in $\sim 85-90 \%$ of the cell population being imaged. Image analysis was performed with the IN Cell Investigator Morphology 1 analysis software program, which detects cells based on nuclear staining. Cellular polarisation in response to SDF- $1 \alpha$ stimulation was quantified using the Cell Intensity Coefficient of Variance (CV) parameter, which we have previously used to quantify F-actin distribution in the cell (Freeley et al., 2012).

\subsection{Statistical analysis}

Statistical analysis was performed using the two-tailed Student $t$ test. Effects were deemed to be significant at $\mathrm{p}$ values $<0.05$.

\section{Results}

\subsection{Delivery of siRNAs into stimulated primary human $T$ cells via Nucleofection@ results in a loss of cell viability}

The recommended nucleofection programs for the delivery of siRNAs/plasmids into primary human T cells that have been stimulated with PHA/IL-2 or anti-CD3/CD28 are T20 and $\mathrm{T} 23 .{ }^{1}$ We evaluated these programs for the delivery of siRNAs and silencing of gene expression in PHA/ IL-2-stimulated human T cells with commercially available siRNAs. Delivery of siRNAs into the T cells was assessed with fluorescently-labelled siRNAs (siGLO ${ }^{\mathrm{TM}}$ ) and the cells were analysed by flow cytometry after $4 \mathrm{~h}$. Although the recommended starting concentration for siRNA-mediated gene silencing in stimulated T cells is $30-300 \mathrm{nM}$, we found that transfection efficiency was low when $5 \times 10^{6} \mathrm{~T}$ cells were nucleofected with $300 \mathrm{nM}$ siGLO (19.3\% and 17.7\% transfected cells using programs T20 and T23 respectively) (Fig. 1A). In contrast, we observed that nucleofection with $1000 \mathrm{nM}$ siGLO resulted in higher levels of transfection efficiency and that both programs were similar in terms of the percentage of cells that were transfected (70.5\% and 65.6\% transfected cells for programs T20 and T23 respectively; Fig. 1A). Transfection efficiencies with $\mathrm{T}$ cells isolated from five independent donors using $1000 \mathrm{nM}$ siGLO and program T20 revealed a mean transfection efficiency of 68\% (range 5688\%) $4 \mathrm{~h}$ post-nucleofection (data not shown). Mock nucleofections served as controls in all experiments whereby $\mathrm{T}$ cells were incubated with the T cell nucleofector@ solution in the presence of $1000 \mathrm{nM}$ siGLO, but these cells were not subjected to nucleofection. Minimal uptake of siGLO was observed in T cells subjected to muck nucleofections after

\footnotetext{
${ }^{1}$ (http://bio.lonza.com/fileadmin/groups/marketing/Downloads/Protocols/ Generated/Optimized_Protocol_73.pdf.)
}

$4 \mathrm{~h}$ (Fig. 1A). As $1000 \mathrm{nM}$ siGLO resulted in efficient siRNA delivery into stimulated T cells using programs T20/T23, we investigated whether gene silencing occurred when the cells were nucleofected with $1000 \mathrm{nM}$ siRNAs targeting the cytoskeletal protein Talin ${ }^{2}$ or $1000 \mathrm{nM}$ of non-targeting control siRNAs. Cells here harvested at 48,72 and $96 \mathrm{~h}$ and Western blotting was performed on lysates prepared at these times. As shown in Fig. 1B, silencing of Talin expression was observed after 48-96 h when program T20 was used for nucleofection, resulting in $~ 50 \%$ gene silencing (Fig. 1B).

We noted however that nucleofection of stimulated T cells with programs T20 or T23 perturbed cell viability when analysed after $72 \mathrm{~h}$, which are times when cells transfected with siRNAs are routinely harvested for evaluation of gene silencing and for functional analysis. For example, whereas cell viability from the mock nucleofections was virtually $100 \%$ after $72 \mathrm{~h}$, T cells that were subjected to nucleofection with programs T20/T23 in the presence of siRNAs had reduced numbers of viable cells (Fig. 2A). The loss of cell viability following nucleofection was independent of the siRNAs used, as similar results were observed when control siRNAs or Talin siRNAs were substituted for siGLO siRNAs (Fig. 2B) and when siRNAs were omitted altogether (data not shown). Furthermore, the T cell nucleofector(B) solution was not toxic to the cells, as cell viability was comparable when mock nucleofections were compared to T cells incubated in PBS (Fig. 2B). While we used PHA/IL-2-stimulated human T cells for the majority of experiments described in this study, a loss of cell viability was also observed when nucleofection was used to deliver siRNAs into purified human $\mathrm{CD} 4{ }^{+} \mathrm{T}$ cells that had been pre-stimulated with anti-CD3/CD28 and IL-2 (Fig. 2C and D).

We next investigated whether viable cells remaining after the nucleofection procedure, as determined by trypan blue staining, were functional or not. For these experiments equal numbers of viable cells from mock nucleofections and cells nucleofected with program T20 were incubated with CellTiter-Blue $₫$ for $4 \mathrm{~h}$. This assay measures the ability of living cells to metabolically convert the redox dye resazurin into the fluorescent product resorufin. We observed that the viable cells that remained after nucleofection could generate the fluorescent product resorufin almost to a similar extent as mock nucleofections, implying that these cells were metabolically functional (Fig. 2E). Similar results were obtained with stimulated $\mathrm{CD}^{+}{ }^{+} \mathrm{T}$ cells (Fig. $2 \mathrm{~F}$ ). We also investigated whether cells that survived the nucleofection procedure using programs T20/T23 were perturbed in their responsiveness to chemokine stimulation in comparison to mock nucleofections. Stimulation of T cells with chemokines such as SDF-1 $\alpha$ results in cellular polarisation as a result of the redistribution of the F-actin network to one end of the cell and the formation of a leading edge (Thelen and Stein, 2008). $1000 \mathrm{nM}$ of control non-targeting siRNAs was nucleofected into $\mathrm{T}$ cells using programs T20/T23 while mock nucleofections were incubated with similar concentrations of siRNAs. Equal numbers of viable cells were harvested after $72 \mathrm{~h}$ and then stimulated with SDF- $1 \alpha$, followed by fixation and staining with Hoechst

\footnotetext{
${ }^{2}$ siRNAs targeting Talin were validated in Jurkat and HuT-78 $\mathrm{T}$ cell lines and resulted in $>80 \%$ silencing of Talin expression when analysed at the protein level after $72 \mathrm{~h}$ by Western blotting (data not shown).
} 
A

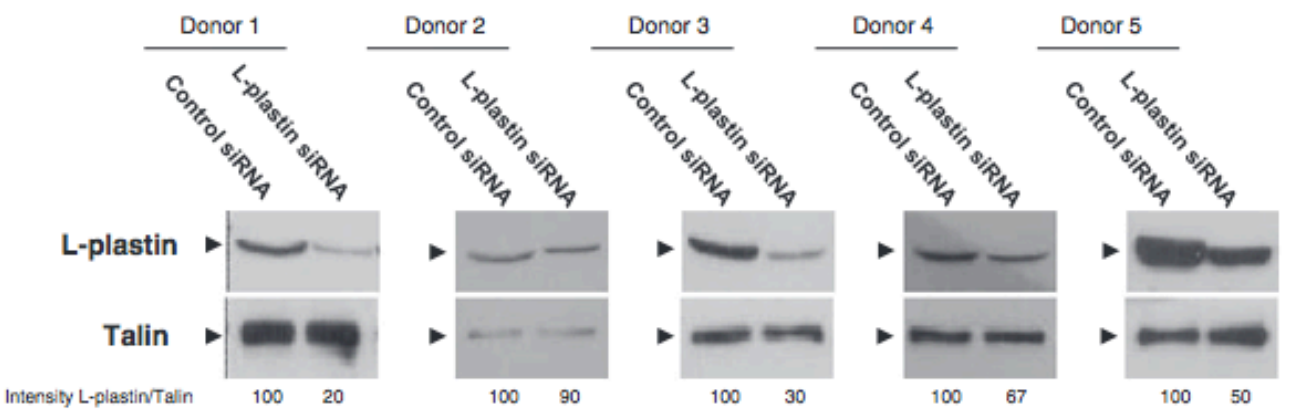

B

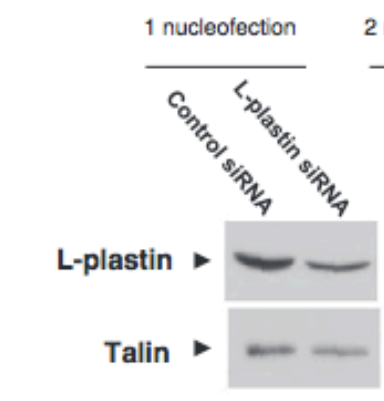

2 nucleofections

Intensity L-plastin/Talin

$100 \quad 56$

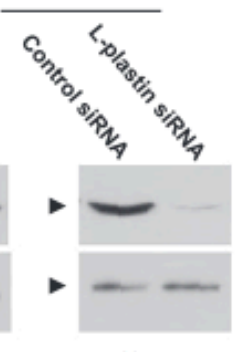

$100 \quad 4$

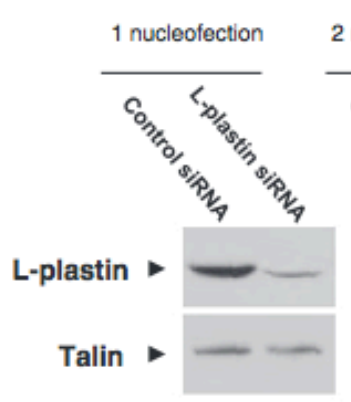

2 nucleofections

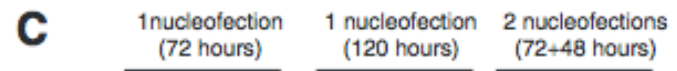

(72 hours) (120 hours) (72+48 hours)
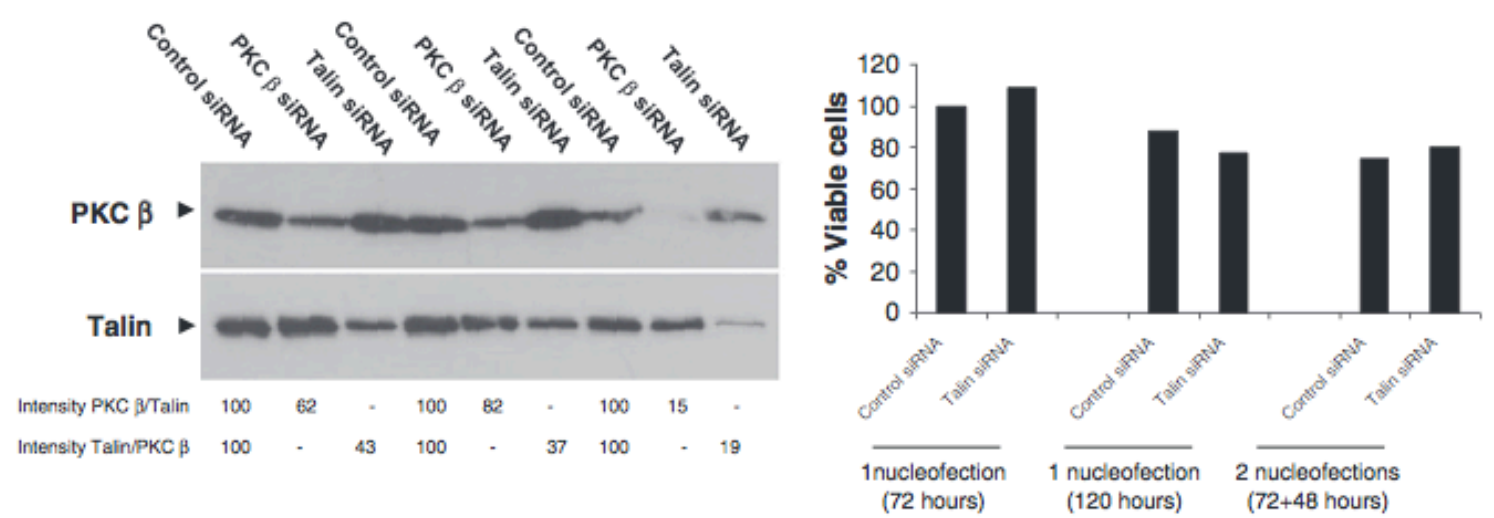

Fig. 4. A two-hit nucleofection strategy significantly increases gene silencing in stimulated human T cells. (A) PHA/IL-2-stimulated T cells from five separate donors were nucleofected with $1000 \mathrm{nM}$ control siRNAs or siRNAs targeting L-plastin using program T7. Cell lysates were prepared after 72 h and probed by Western blotting with antibodies to L-plastin or Talin (loading control). Densitometry was used to estimate the intensity of the bands and is expressed as Intensity L-plastin/Talin. (B) PHA/IL-2-stimulated T cells from two separate donors were nucleofected with $1000 \mathrm{nM}$ control siRNAs or siRNAs targeting L-plastin using program T7 in duplicate. One set of samples was harvested after $72 \mathrm{~h}$ (1 nucleofection) while the second set of samples was nucleofected again with $1000 \mathrm{nM}$ control siRNAs or L-plastin siRNAs ( 2 nucleofections). The second set of samples was harvested after a further $48 \mathrm{~h}$ (120 h total). Cell lysates were probed by Western blotting with antibodies to L-plastin or Talin (loading control). The exposure times of all the blots from both donors were identical. Densitometry was used to estimate the intensity of the bands and is expressed as Intensity L-plastin/Talin. (C) PHA/IL-2-stimulated T cells were nucleofected with $1000 \mathrm{nM}$ control siRNAs or siRNAs targeting PKC $\beta$ using program T7 using a single or two-hit nucleofection strategy as outlined in (B) above. Cell lysates were prepared at $72 \mathrm{~h}$ or $120 \mathrm{~h}$ and probed by Western blotting with antibodies to PKC $\beta$ or Talin. Talin served as a loading control for gene silencing of PKC $\beta$ whereas PKC $\beta$ served as a loading control for Talin silencing. Densitometry was used to estimate the intensity of the bands and is expressed as Intensity PKC $\beta$ /Talin or Intensity Talin/PKC $\beta$. (D) Cell viability of T cells subjected to one or two nucleofections was measured at the indicated times. The data in this figure is representative of at least two similar experiments.

33258 and phalloidin-TRITC to label the nucleus and F-actin, respectively. The number of cells that re-distributed their F-actin to one end of the cell in response to SDF- $1 \alpha$ stimulation was determined by High Content Analysis using an acquisition procedure that imaged $85-90 \%$ of the cell population (see Materials and Methods section for more information). F-actin localisation in the cell population was quantified with the Cell Intensity Coefficient of Variance (CV) parameter
(Freeley et al., 2012). Cell Intensity CV measures the homogeneity of staining in the cell - cells that display homogenous staining of a particular protein or stain have low Cell Intensity $\mathrm{CV}$ values, while cells with non-homogenous/polarised distribution of a particular protein or stain have higher Cell Intensity $\mathrm{CV}$ values. The Cell Intensity CV values for F-actin staining in non-polarised $\mathrm{T}$ cells in these experiments were typically 0.2 , while polarised cells with F-actin distributed at one end of 
the cell had Cell Intensity CV values in the range of 0.3-0.4 (Fig. 2G). Using the Cell Intensity CV parameter as a read-out of F-actin distribution in the cell, we determined that nucleofection of T cells with programs T20 or T23 perturbed the total number of cells that re-distributed their F-actin to the leading edge in comparison to mock nucleofections (Fig. 2G). In summary, these studies indicate that the recommended nucleofection programs for stimulated primary human $\mathrm{T}$ cells result in siRNA delivery and gene silencing, but this is associated with a loss of cellular proliferation and cell viability. While the metabolic capacity of viable cells that survive the nucleofection procedure is not substantially affected, these cells are perturbed in their responsiveness to chemokine stimulation.

\subsection{Evaluation of other programs for nucleofection of stimulated human $T$ cells}

As the recommended nucleofection programs for stimulated T cells affected cell viability, we evaluated a number of other programs (T6, T9 and P7) and compared them to program T20. These new programs were based on information received from the technical staff at Lonza. Programs T3 and T7 were also included after an extensive search of the literature, as these programs were used for nucleofection of mRNA into stimulated primary T cells (Rabinovich et al., 2006). For our study described here, nucleofection programs were evaluated using siGLO siRNAs with the goal of defining non-toxic or less-toxic nucleofection programs for siRNA delivery and gene silencing. Transfection efficiency was measured by flow cytometry after $4 \mathrm{~h}$ and cell viability was measured after $72 \mathrm{~h}$ using $\mathrm{T}$ cells from two independent donors. The results are summarised in Fig. 3A. As previously outlined, we observed that nucleofection of siGLO into PHA/IL-2-stimulated primary human T cells using program T20 resulted in satisfactory transfection efficiency but was associated with a loss of cell viability when compared to mock nucleofections performed in parallel (Fig. 3A). We found that program T3 was inefficient for the delivery of siGLO into the cells. Program T9 resulted in slightly lower transfection efficiencies compared to program T20, but this program was also associated with a loss of cell viability. In contrast, nucleofection programs T6, T7 and P7 resulted in a lower transfection efficiency compared to program T20 but cell viability was not perturbed (Fig. 3A).

Program T7 was evaluated further for silencing of gene expression using siRNAs targeting Talin or L-plastin, while non-targeting siRNAs were used as controls. Cell lysates were prepared after 48, 72 and $96 \mathrm{~h}$ and the levels of expression of Talin or L-plastin were analysed by Western blotting using specific antibodies. We observed that silencing of Talin and L-plastin expression was observed with $1000 \mathrm{nM}$ siRNAs after 48-96 h (Fig. 3B). In fact, a direct comparison of program T7 with program T20 demonstrated that program T7 resulted in comparable silencing of Talin or L-plastin expression as program T20 (Supplementary Fig. 1A). Furthermore, program T7 performed better than program T20 in terms of the total number of cells that re-distributed their F-actin to one side of the cell in response to SDF- $1 \alpha$ stimulation, albeit the number of responsive cells was slightly lower in comparison to mock nucleofections (Fig. 3C). We also showed that the $\mathrm{T}$ cell nucleofector solution from Lonza could be substituted with the Ingenio electroporation solution (sold by Mirus Bio) for nucleofection of $\mathrm{T}$ cells using program T7, as these solutions were equivalent in terms of siRNA delivery using siGLO (Fig. 3D) and upon silencing of Talin expression with siRNAs (Fig. 3E). Furthermore, the number of viable cells that were recovered after nucleofection at $72 \mathrm{~h}$ was similar for both solutions (data not shown).

\subsection{A two-hit nucleofection strategy significantly increases gene silencing in stimulated human T cells}

Having optimised the program for nucleofection of stimulated human T cells, we noticed variability in the level of gene silencing following nucleofection of siRNAs targeting L-plastin using $\mathrm{T}$ cells from five different donors (Fig. 4A). Satisfactory gene silencing was observed in two donors ( $70 \%$ and $80 \%$ reduction in L-plastin expression levels), while moderate gene silencing was observed in another donor ( $50 \%$ reduction in L-plastin expression levels). In contrast, poor gene silencing was observed in two other donors (10\% and $33 \%$ reduction in L-plastin expression levels), giving an average reduction in L-plastin expression levels of $48.6 \%$ from the five donors. We therefore investigated whether a second nucleofection of siRNAs, delivered to the cells $72 \mathrm{~h}$ after the initial nucleofection, would improve gene silencing in T cells. The cells were harvested $48 \mathrm{~h}$ after the second nucleofection (i.e. $120 \mathrm{~h}$ after the initial nucleofection). As shown in Fig. 4B, a second nucleofection dramatically improved gene silencing of L-plastin using stimulated $\mathrm{T}$ cells from two separate donors. For example, a single nucleofection of $1000 \mathrm{nM}$ siRNA targeting L-plastin in the first donor resulted in moderate gene silencing ( $44 \%$ reduction in L-plastin expression levels), while a second nucleofection of $1000 \mathrm{nM}$ siRNAs to the same cells after $72 \mathrm{~h}$ resulted in more effective gene silencing (96\% reduction in L-plastin expression levels). A similar result was observed with the second donor, as a single nucleofection of siRNAs resulted in satisfactory gene silencing (75\% reduction in L-plastin expression levels), while a second nucleofection after $72 \mathrm{~h}$ enhanced gene silencing further (93\% reduction in L-plastin expression levels) (Fig. 4B). This two-hit nucleofection strategy was subsequently used for the silencing of L-plastin expression in stimulated T cells (Freeley et al., 2012) and yielded an average reduction in L-plastin expression levels of $80.2 \%$ from fourteen separate donors (data not shown). This two-hit nucleofection strategy was not a phenomenon restricted to L-plastin, as an identical procedure also resulted in more effective gene silencing of Talin and PKC $\beta$ (Fig. 4C). Importantly, we also showed that this enhanced gene silencing effect using two nucleofections over a period of $120 \mathrm{~h}$ was in fact due to the second nucleofection of siRNAs and not due to leaving cells that were nucleofected once for a similar period of time (Fig. 4C). Effective gene silencing of $80-100 \%$ was also obtained for 6 of the 7 PKC isoforms that are expressed in primary human T cells (Freeley et al., 2012) and 75-90\% silencing of 8 other proteins that we have tested (data not shown). Importantly, neither the first (Fig. 3A) nor second (Fig. 4D) nucleofection hit substantially affects cell viability. Furthermore, the total number of viable cells that re-distributed their F-actin to one side of the cell in response to SDF- $1 \alpha$ 
stimulation was similar between cells nucleofected once using program T7 and cells nucleofected with the two-hit strategy (Supplementary Fig. 1B). This two hit nucleofection strategy was also shown to result in effective silencing of gene expression in anti-CD3/CD28-stimulated human $T$ cells (Freeley et al., 2012). We have therefore characterised a two-hit nucleofection strategy that results in efficient gene silencing in stimulated primary human $\mathrm{T}$ cells that does not impact on cell viability.

\section{Discussion}

In this study we have optimised a two-hit nucleofection strategy for siRNA-mediated gene silencing in stimulated primary human $\mathrm{T}$ cells. This new and improved procedure was developed because initial attempts to investigate the role of candidate proteins in $\mathrm{T}$ cell function using siRNAs resulted in losses in cell viability when the recommended nucleofection programs were used. Furthermore, viable cells that survived the nucleofection process were perturbed in their responsiveness to chemokine stimulation. While loss of cell viability and functionality is perhaps not unexpected because of the nucleofection procedure, we demonstrate here that a relatively simple two-hit nucleofection siRNA strategy using an alternative program (T7) results in effective gene silencing of a wide number of targets in primary stimulated human T cells. Importantly, cell viability is only minimally perturbed when $T$ cells are subjected to this optimised protocol for gene silencing experiments and their responsiveness to chemokine stimulation is maintained. Hence, this protocol is an improvement over the recommended siRNA delivery protocol provided by the manufacturer for stimulated $\mathrm{T}$ cells.

The nucleofection procedure is based on the principle of electroporation, with proprietary cell-type specific solutions and optimised programs used for the delivery of plasmids and siRNAs into a wide variety of cell types, including hardto-transfect cells such as primary $T$ cells and neurons (Gresch et al., 2004). Indeed, this method is now one of the most commonly used methods for gene transfection and gene silencing in T cells. Programs U14 and V24 are recommended for nucleofection of unstimulated primary human $\mathrm{T}$ cells, while programs T20 and T23 are recommended for nucleofection of stimulated primary human T cells. When we evaluated nucleofection technology for the delivery of siRNAs into stimulated primary human $\mathrm{T}$ cells using the recommended T20/T23 programs, we found that although siRNAs were delivered into the cells and resulted in gene silencing, we also observed substantial losses in cell viability. Furthermore, the viable cells that were recovered following nucleofection responded poorly to stimulation with chemokines. Hence, this procedure made it quite difficult to uncover putative roles for genes/proteins of interest in T cell activation or migration. Our results also revealed that the loss in cell viability was primarily a result of the nucleofection programs used, rather than the T cell nucleofector solution or the siRNAs, and therefore required alternative programs to be evaluated. Our finding that the recommended programs for nucleofection of $\mathrm{T}$ cells result in losses in cell viability is in agreement with Rabinovich et al., as this group reported high levels of cell death when programs T20/T23 was used for nucleofection of plasmids encoding GFP or mRNA encoding an anti-CD19 chimeric immune receptor into stimulated primary human T cells (Rabinovich et al., 2006). Hence, the recommended nucleofection programs for individual cell types may not always be ideal, requiring optimisation of new programs/protocols or adaptation of existing ones (Goffinet and Keppler, 2006). Along this line, Ward and colleagues have also reported that nucleofection of siRNAs into unstimulated human T cells using the recommended V24 program resulted in very high levels of cell death when the cells were stimulated post-nucleofection (Smith et al., 2007).

We evaluated a number of alternative nucleofection programs for siRNA delivery and gene silencing in stimulated $T$ cells and found a number of programs that resulted in lower levels of siGLO delivery than the recommended program T20 but were less toxic (Fig. 3A). Our finding that program T7 was less toxic than program T20 is also in agreement with Rabinovich et al., who reported that program T7 was more suitable than program T20 for the delivery of plasmids or mRNA into stimulated T cells (Rabinovich et al., 2006). In their study, $90 \%$ of the $T$ cell population expressed the anti-CD19 chimeric immune receptor on the cell surface when mRNA encoding this construct was nucleofected into the cells using program T7, with cell viability greater than 90\% (Rabinovich et al., 2006). In contrast with Rabinovich et al., however, we found that program T3 was far less effective than program $\mathrm{T} 7$ for nucleofection of siRNAs into $\mathrm{T}$ cells (Fig. 3A). In fact, our results demonstrated that a different program, T9, was better than program $\mathrm{T} 7$ in terms of transfection efficiency of siRNAs, albeit that cell viability was reduced (Fig. 3A).

While the T7 program is therefore suitable for the delivery of nucleotides such as siRNAs and mRNA into stimulated $\mathrm{T}$ cells, it should be noted however that there are significant differences in the fates of mRNA and siRNA once they are delivered into the cell. Translation of mRNA into protein occurs rapidly in the cell cytoplasm (within hours) (Rabinovich et al., 2006), whereas siRNA-mediated gene silencing (i.e. processing by the siRNA machinery, inhibition of mRNA translation and turnover of the protein) also takes place in the cytosol but usually requires 24-96 h (Aagaard and Rossi, 2007; Singh et al., 2011). We therefore needed to evaluate whether gene silencing occurs when stimulated $\mathrm{T}$ cells are nucleofected with siRNAs using program T7. Indeed, we found that program T7 was suitable for gene silencing studies in stimulated T cells using siRNAs, as confirmed by the silencing of Talin or L-plastin expression (Fig. 3B). While program T7 was suitable for siRNA delivery and gene silencing, variations observed in both siRNA delivery (Fig. 3A) and gene silencing (Fig. 4A) using $\mathrm{T}$ cells from different donors promoted us to explore whether a second nucleofection after $72 \mathrm{~h}$ would significantly improve gene silencing. A major finding from our work was that a second nucleofection hit using program T7 dramatically improved gene silencing while minimally impacting upon cell viability. We speculate that allowing the cells to recover for $72 \mathrm{~h}$ prior before carrying out the second nucleofection hit allows the cells sufficient time to recover and avoids overloading the siRNA machinery. We have recently utilised this two-hit nucleofection procedure for gene silencing of 6 of 7 PKC isoforms that are expressed in stimulated primary human $\mathrm{T}$ cells (80-100\% gene silencing at the protein level) (Freeley et al., 2012) and for 8 other proteins that we have tested 
(75-90\% gene silencing; data not shown). While we have developed an optimised method for gene silencing in stimulated T cells that is an improvement over the protocol recommended by the manufacturer, it is also interesting to note that a number of groups have employed alternative nucleofection programs and protocols for silencing of gene expression in stimulated primary human $T$ cells other than those recommended by the manufacturer or with the program that we have characterised here (Morin et al., 2008; Baldauf et al., 2012). However, unlike our study presented here, no comparisons have been made between these alternative programs/protocols and those recommended by the manufacturer in terms of siRNA delivery, gene silencing and cell viability and function.

While we have shown that a two-hit nucleofection protocol enhances silencing of gene expression in stimulated T cells, other groups have used different methods to increase the efficiency of gene silencing in primary $\mathrm{T}$ cells with siRNAs. These include enrichment of the transfected $\mathrm{T}$ cell population following nucleofection (Tahvanainen et al., 2006) and prolonging gene silencing in T cells through the use of stabilised siRNAs (Mantei et al., 2008). For example, Tahvanainen et al. used nucleofection for the delivery of a plasmid encoding an shRNA in combination with a gene encoding a cell surface marker into murine $T$ cells (Tahvanainen et al., 2006). Expression of the cell surface marker permitted enrichment of the nucleofected population using antibody-coated magnetic beads and thus the non-transfected cell population was removed. In contrast, Mantei et al. demonstrated that siRNA-mediated gene silencing was short-lived in primary $\mathrm{T}$ cells and that chemical modification of the siRNAs to increase their stability prolonged gene silencing in-vitro and when the cells were adoptively transferred into mice (Mantei et al., 2008). The finding from this group that siRNA stability is a key parameter for efficient gene silencing in $\mathrm{T}$ cells suggests that our two hit nucleofection protocol may increase the stability of the siRNAs inside the cells and thus prolong the duration of gene silencing. However, our observation that the levels of expression of Talin, L-plastin and PKC $\beta$ do not recover after $120 \mathrm{~h}$ when a single nucleofection is used to deliver siRNAs into the cells (Fig. 4C) suggests that siRNA instability is not the mechanism why an additional nucleofection increases the efficiency of gene silencing. We believe that it is likely that the second nucleofection hit reduces the pool of non-transfected T cells and this leads to greater gene silencing. It is noteworthy that two-hit nucleofection strategies have also recently been used for siRNA-mediated gene silencing in naive primary human $\mathrm{CD}^{+} \mathrm{T}$ cells (Wabnitz et al., 2010; Li et al., 2011; Budhiraja et al., 2012).

Understanding the pathways that regulate $\mathrm{T}$ cell function offers the potential to target these proteins therapeutically in order to modulate T cell-mediated inflammatory/autoimmune diseases, immunosuppression and cancer (June et al., 2009; Steward-Tharp et al., 2010; Restifo et al., 2012). Silencing of gene expression with siRNAs is one mechanism that is currently being explored for modulation of $\mathrm{T}$ cell signalling in-vivo. For example, viral-based delivery systems (June et al., 2009), antibodies conjugated to particles or peptides (Kumar et al., 2008; Peer et al., 2008; Peer and Shimaoka, 2009), RNA aptamers (Neff et al., 2011) carbon nanotubes and nanoparticles (Liu et al., 2007; Zhou et al., 2011), Accellmodified siRNAs (Chehtane and Khaled, 2010; Fausther-
Bovendo et al., 2010) and peptide transduction domains (Eguchi and Dowdy, 2009) have all been shown to be effective for the delivery of siRNAs into primary $\mathrm{T}$ cells, with some of these strategies demonstrated to successfully manipulate $T$ cell function in animal models of inflammatory disease, cancer and infection. Furthermore, silencing of gene expression with siRNAs in primary mouse $T$ cells via nucleofection, followed by adoptive transfer of the cells into recipient mice, has been demonstrated to be efficacious in models of inflammatory diseases (Amarnath et al., 2011; Moriwaki et al., 2011) and cancer (Hinterleitner et al., 2012). The new and improved nucleofection procedure that we have optimised here adds to the repertoire of methods for successful gene silencing in primary $\mathrm{T}$ cells and will therefore have benefits for both basic and translational research.

Supplementary data to this article can be found online at http://dx.doi.org/10.1016/j.jim.2013.08.005.

\section{References}

Aagaard, L, Rossi, J.J. 2007. RNAi therapeutics: principles, prospects and challenges. Adv. Drug Deliv. Rev. 59, 75-86.

Amamath, S, Mangus, CW. Wang, J.C., Wei, F., He, A., Kapoor, V., Foley, J.E. Massey, P.R., Felizardo, T.C., Riley, J.L, Levine, B.L., June, C.H., Medin, J.A. Fowler, D.H., 2011. The PDL1-PD1 axis converts human TH1 cells into regulatory T cells. Sci. Transl. Med. 3, 111ra120.

Baldauf, H.M. Pan, X. Erikson, E., Schmidt, S., Daddacha, W. Burgeraf, M. Schenkova, K., Ambiel, 1., Wabnitz, G., Gramberg. T., Panitz, S., Flory, E. Landau, N.R., Sertel, S., Rutsch, F., Lasitschka, F., Kim, B., Konig. R., Fackler. 0.T., Keppler, 0.T., 2012. SAMHD1 restricts HIV-1 infection in resting CD4(+) T cells. Nat. Med. 18, 1682-1687.

Bradley, LM., 2003. Migration and T-lymphocyte effector function. Curr. Opin. Immunol. 15, 343-348.

Budhiraja, S, Ramakrishnan, R., Rice, A.P. 2012. Phosphatase PPM1A negatively regulates $\mathrm{P}$-TEFb function in resting CD4T $+\mathrm{T}$ cells and inhibits HIV-1 gene expression. Retrovirology 9, 52.

Chehtane, M., Khaled, A.R., 2010. Interleukin-7 mediates glucose utilization in lymphocytes through transcriptional regulation of the hexokinase II gene. Am. J. Physiol. Cell Physiol. 298, C1560-C1571.

Cohen, P., 2010. Guidelines for the effective use of chemical inhibitors of protein function to understand their roles in cell regulation. Biochem. J. $425,53-54$

Eguchi, A., Dowdy, S.F., 2009. siRNA delivery using peptide transduction domains. Trends Pharmacol. Sci. 30, 341-345.

Fausther-Bovendo, H., Vieillard, V., Sagan, S., Bismuth, G., Debre, P. 2010. HIV gp41 engages gClqR on CD4 $+\mathrm{T}$ cells to induce the expression of an NK ligand through the PIP3/ $\mathrm{H}_{2} \mathrm{O}_{2}$ pathway. PLoS Pathog. 6, e1000975.

Freeley, M., O'Dowd, F., Paul, T., Kashanin, D., Davies, A., Kelleher, D., Long. A. 2012. L-plastin regulates polarization and migration in chemokinestimulated human T lymphocytes. J. Immunol. 188, 6357-6370.

Gehl, J., 2003. Electroporation: theory and methods, perspectives for drug delivery, gene therapy and research. Acta Physiol. Scand. 177, 437-447.

Ghoreschi, K. Laurence, A., O'Shea, J.J., 2009. Selectivity and therapeutic inhibition of kinases: to be or not to be? Nat. Immunol. 10, 356-360.

Goffinet, C., Keppler, O.T., 2006. Efficient nonviral gene delivery into primary lymphocytes from rats and mice. FASEB J. 20, 500-502.

Gresch, O., Engel, F.B., Nesic, D., Tran, T.T., England, H.M., Hickman, E.S. Korner, L., Gan, L., Chen, S., Castro-Obregon, S., Hammermann, R., Wolf, J. Muller-Hartmann, H., Nix, M., Siebenkotten, G., Kraus, G., Lun, K., 2004 New non-viral method for gene transfer into primary cells. Methods 33. 151-163.

Haan, C., Behrmann, 1., 2007. A cost effective non-commercial ECL-solution for Western blot detections yielding strong signals and low background. Immunol. Methods 318, 11-19.

Hinterleitner, R. Gruber, T., Pfeifhofer-Obermair, C., Lutz-Nicoladoni, C., Tzankov, A., Schuster, M., Penninger, J.M., Loibner, H., Lametschwandtner. G. Wolf, D. Baier, G, 2012. Adoptive transfer of siRNA Cblb-silenced CD8(+) T lymphocytes augments tumor vaccine efficacy in a B16 melanoma model. PLoS One 7, e44295.

Hurez, V., Hautton, R.D., Oliver, J., Matthews, R.]., Weaver, C.K., 2002. Gene delivery into primary $T$ cells: overview and characterization of transgenic model for efficient adenoviral transduction. Immunol. Res. 26, 131-141. 
June, C.H., Blazar, B.R., Riley, J.1., 2009. Engineering lymphocyte subsets: tools, trials and tribulations. Nat. Rev. Immunol. 9, 704-716.

Kumar, P. Ban, H.S., Kim, S. ., Wu, H. Pearson, T., Greiner, D.., Laouar, A, Yao, J. Haridas, V., Habiro, K. Yang Y.G., Jeong, J.H., Lee, K.Y., Kim, Y.H., Kim, S.W. Peipp, M., Fey, G.H., Manjunath, N., Shultz, L.D. Lee, S.K., Shankar, P., 2008. T cell-specific siRNA delivery suppresses HIV-1 infection in humanized mice. Cell 134, 577-586

Lefort, C.,. Kim, M., 2010. Human T Lymphocyte Isolation, Culture and Analysis of Migration In Vitro. J. Vis. Exp. (40), e2017. http://dx.doiorg/ 10.3791/2017.

Li, F.Y., Chaigne-Delalande, B., Kanellopoulou, C., Davis, J.C., Matthews, H.F. Douek, D.C., Cohen, J.., Uzel, G., Su, H.C. Lenardo, M.J., 2011. Second messenger role for $\mathrm{Mg} 2+$ revealed by human T-cell immunodeficiency. Nature 475, 471-476.

Liu, Z, Winters, M., Holodniy, M., Dai, H., 2007, siRNA delivery into human T cells and primary cells with carbon-nanotube transporters. Angew. Chem. Int. Ed. Engl. 46, 2023-2027.

Mantei, A., Rutz, S., Janke, M., Kirch hoff, D.Jung, U., Patzel, V., Vogel, U., Rudel, T. Andreou, L., Weber, M., Scheffold, A., 2008, siRNA stabilization prolongs gene knockdown in primary T lymphocytes. Eur. J, Immunol. 38, 2616-2625.

Morin, N.A., Oakes, P.W.. Hyun, Y.M. Lee, D., Chin, Y.E., King, M.R., Springer. T.A., Shimaoka, M., Tang. J.X., Reichner, J.S., Kim, M., 2008. Nonmuscle myosin heavy chain IIA mediates integrin LFA-1 de-adhesion during ? lymphocyte migration. J. Exp. Med. 205, 195-205.

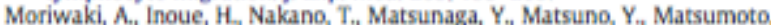
T. Fukuyama, S. Kan, O.K., Matsumoto, K., Tsuda-Eguchi, M., Nagakubo. D. Yoshie, O., Yoshimura, A. Kubo, M. Nakanishi, Y., 2011. T cell treatment with small interfering RNA for suppressor of cytokine signaling 3 modulates allergic airway responses in a murine model of asthma. Am. J. Respir. Cell Mol. BioL. 44, 448-455.

Neff, C.P. Zhou, J., Remling, L. Kuruvilla, J., Zhang. J., Li, H., Smith, D.D. Swiderski. P. Rossi. J... Akkina, R.. 2011. An aptamer-siRNA chimera suppresses HIV-1 viral loads and protects from helper $\mathrm{CDA}(+) \mathrm{T}$ cell decline in humanized mice. Sci. Transl. Med. 3, 66ra6.

Peer, D., Shimaoka, M. 2009. Systemic siRNA delivery to leukocyte-implicated diseases. Cell Cycle 8, 853-859.

Peer, D., Park, E.J., Morishita, Y., Carman, C.V., Shimaoka, M., 2008, Systemic leukocyte-directed siRNA delivery revealing cyclin D1 as an antiinflammatory target. Science 319, 627-630.
Perlmutter, R.M., Alberola-lla, J., 1996. The use of dominant-negative mutations to elucidate signal transduction pathways in lymphocytes. Curr. Opin. ImmunoL. 8, 285-290.

Rabinovich, P.M., Komarovskaya, M.E., Ye, Z.J., Imai, C. Campana, D., Bahceci, E., Weissman, S.M., 2006. Synthetic messenger RNA as a tool for gene therapy. Hum. Gene Ther. 17, 1027-1035.

Restifo, N.P., Dudley, M.E., Rosenberg, S.A. 2012. Adopcive immunotherapy for cancer: harnessing the T cell response. Nat. Rev. Immunol. 12, 269-281.

Saveliev, A., Tybulewicz, V.L., 2009. Lymphocyte signaling: beyond knockouts. Nat. Immunol. 10, 361-364.

Singh, S. Narang, A.,., Mahato, R.I., 2011. Subcellular fate and off-target effects of siRNA, shRNA, and miRNA. Pharm. Res. 28, 2996-3015.

Smith, L.D., Hickman, E.S., Parry, R.V.. Westwick, J., Ward, S.G. 2007. p13Kgamma is the dominant isoform involved in migratory responses of human T lymphocytes: effects of ex vivo maintenance and limitations of non-viral delivery of siRNA. Cell. Signal. 19, 2528-2539.

Song. J. Lei, F,T., Xiong, X., Haque, R., 2008. Intracellular signals of T cell costimulation. Cell. Mol. Immunol. 5, 239-247.

Steward-Tharp, S.M., Song. Y.J., Siegel, R.M., O'Shea, J.J., 2010. New insights into $\mathrm{T}$ cell biology and $\mathrm{T}$ cell-directed therapy for autoimmunity, inflammation, and immunosuppression. Ann. N. Y. Acad. Sci. 1183, 123-148.

Tahvanainen, I. Pykalainen, M., Kallonen, T., Lahteenmaki, H., Rasool, O., Lahesmaa, R., 2006. Enrichment of nucleofected primary human CD4 - T cells: a novel and efficient method for studying gene function and role in human primary T helper cell differentiation. J. Immunol, Methods 310. 30-39.

Thelen, M., Stein, J.V., 2008. How chemokines invite leukocytes to dance. Nat, Immunol, 9, 953-959.

Wabnitz, G.H., Lohneis, P. Kirchgessner, H., Jahraus, B., Gottwald, S., Konstandin, M. Klemke, M. Samstag. Y., 2010. Sustained LFA-1 cluster formation in the immune synapse requires the combined activities of L-plastin and calmodulin. Eur. J. Immunol, 40, 2437-2449.

Zhou, J., Neff, C.P., Liu, X., Zhang. J. L. H., Smith, D.D., Swiderski, P., Aboellail, T., Huang, Y., Du, Q. Liang Z., Peng. L. Akkina, R. Rossi, J., 2011. Systemic administration of combinatorial dsiRNAs via nanoparticles efficiently suppresses HIV-1 infection in humanized mice. Mol. Ther. 19. $2228-2238$. 